\title{
MISMATCH REPAIR GENES IN COLORECTAL CARCINOMA
}

\author{
Asim Qureshi, Imran N. Ahmad \\ Department of Pathology, Shifa International Hospital, Islamabad \\ Received: 12 February 2015 / Accepted: 24 April 2015
}

Microsatellite instability (MSI) results from defective DNA produced as an end result of mismatch. Approximately $12-18 \%$ of colorectal carcinomas show MSI. MSI is the result of defects in genes hMLH1, hMSH2, hPMS1, hPMS2 and GTBP/hMSH6 ${ }^{[1]}$ Tumours which have MSI are called MSI-H. MSI-H tumours are significant predictors of disseminated disease in colorectal cancer ${ }^{[2]}$ Tumours on the right side of colon (caecum/ascending colon), those in patients younger than 50 years and those with medullary or

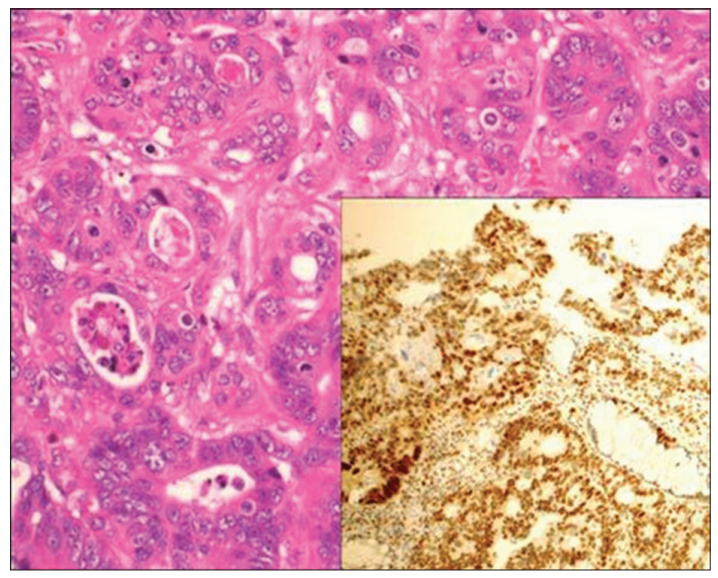

Figure 1: The figure shows adenocarcinoma of rectum, moderately differentiated, hematoxylin and eosin stained slide at $\times 40$ magnification. Immunohistochemical stain MLH 1 (inset) shows positive staining in the tumour cells as well as benign epithelial cells (acting as positive internal control) signet ring morphology are suggestive of mismatch repair (MMR) loss and should be screened for MMR proteins by immunohistochemistry (IHC). The results of IHC should be interpreted and subsequently followed up as follows:

- All four proteins are present and there is no family history ( $80 \%$ of total cases): Stop further testing.

- MLH 1 and PMS 2 are absent (15\% of total cases): Check for BRAF mutation analysis: If present, stop testing: If negative, sequence for gene rearrangement.

- MSH 2 and/or MSH 6 absent (5\% of total cases): Sequence for gene rearrangement.

Positive staining demonstrates that the tumour is negative for MSI. A negative staining would mean tumour is MSI high or microsatellite unstable.

\section{Conflict of Interest}

The authors declare that they have no conflict of interest.

\section{References}

1. Yang L, Sun Y, Huang XE, et al. Carcinoma microsatellite instability status as a predictor of benefit from fluorouracilbased adjuvant chemotherapy for stage II rectal cancer. Asian Pac J Cancer Prev 2015;16:1545-51.

2. Birgisson $\mathrm{H}$, Edlund $\mathrm{K}$, Wallin $\mathrm{U}$, et al. Microsatellite instability and mutations in BRAF and KRAS are significant predictors of disseminated disease in colon cancer. BMC Cancer 2015;15:1144. 